\title{
Comparison of oral, vaginal and sublingual misoprostol for induction of labour in premature rupture of membranes after 34 weeks of gestation: a randomized controlled trial
}

\author{
Chandana Galidevara $^{1 *}$, Latha Chaturvedula ${ }^{2}$, Syed Habeebullah ${ }^{3}$
}

\author{
${ }^{1}$ Department of Obstetrics and Gynecology, Mahatma Gandhi Medical College and Research Institute, Puducherry, \\ India \\ ${ }^{2}$ Department of Obstetrics and Gynecology, JIPMER, Puducherry, India
}

Received: 16 February 2018

Accepted: 21 February 2018

\section{*Correspondence:}

Dr. Chandana Galidevara,

E-mail: galichandana@gmail.com

Copyright: (C) the author(s), publisher and licensee Medip Academy. This is an open-access article distributed under the terms of the Creative Commons Attribution Non-Commercial License, which permits unrestricted non-commercial use, distribution, and reproduction in any medium, provided the original work is properly cited.

\section{ABSTRACT}

Background: Purpose of this study was to evaluate the efficacy and safety of different routes of administration of misoprostol - $50 \mu \mathrm{g}$ oral, $25 \mu \mathrm{g}$ vaginal and $50 \mu \mathrm{g}$ sublingual for induction of labour in women with premature rupture of membranes after 34 weeks of gestation.

Methods: Women admitted to labour ward with premature rupture of membranes (PROM) after 34 weeks of gestation and requiring induction of labour were randomized into three groups. A total of 246 women participated in the study and were assigned to three groups to receive either $50 \mu \mathrm{g}$ oral misoprostol $(\mathrm{n}=80)$ or $25 \mu \mathrm{g}$ vaginal misoprostol( $n=83)$ or $50 \mu \mathrm{g}$ sublingual misoprostol $(n=83)$. The doses were repeated 4 hourly till active labour was established or up to a maximum of 4 doses. Patient factors, induction to delivery intervals, maternal side effects and fetal outcomes were noted.

Results: The mean induction to active labour interval was not significantly different in the three groups (oral vs vaginal vs sublingual-7.52 \pm 4.8 vs $7.75 \pm 4.1 \mathrm{~h}$ vs $7.68 \pm 5.3 \mathrm{~h} ; \mathrm{p}=0.93$ ). There was no significant difference in the induction to delivery time interval among the three misoprostol groups (oral vs vaginal vs sublingual $-10.9 \pm 5.9 \mathrm{~h}$ vs $11.2 \pm 5.0 \mathrm{~h}$ vs $11.4 \pm 6.6 \mathrm{~h} ; \mathrm{p}=0.88$ ). Spontaneous vaginal delivery rate, instrumental delivery rate and lower segment ceasarean section rates were comparable among the three groups. The number of neonates with APGAR score $<7$ (low APGAR) at 1 minute of birth was highest in sublingual group and lowest in vaginal group which was statistically significant (oral vs vaginal vs sublingual, $16 \%$ vs $7.2 \%$ vs $20.5 \% ; \mathrm{p}=0$. 04 ). APGAR score $<7$ at 5 minutes was not significantly different among the three groups (oral vs vaginal vs sublingual, $4.8 \%$ vs $2.4 \%$ vs $7.2 \%$; $\mathrm{p}=0.2$ ). This implies that the need for immediate resuscitation was more in the sublingual group. Neonatal intensive care admission was least in the vaginal group although the difference was not statistically significant. Sublingual group had a higher rate of hyperstimulation and fetal heart rate abnormalities compared to oral and vaginal groups although these parameters did not reach statistical significance.

Conclusions: Oral, vaginal and sublingual routes of administration of misoprostol are equally effective for labour induction in women with premature rupture of membranes after 34 weeks with sublingual route having slightly higher incidence of low APGAR scores at one minute for the neonate.

Keywords: Induction of labour, Oral misoprostol, Premature rupture of membranes, Sublingual misoprostol, Vaginal misoprostol 


\section{INTRODUCTION}

Spontaneous rupture of membranes before the onset of labour is known as premature rupture of membranes (PROM). ${ }^{1}$ Premature rupture of membranes complicates $5-10 \%$ of pregnancies. The decision to manage PROM expectantly or actively is still controversial and depends on factors such as gestational age, fetal weight, lung maturity and availability of good neonatal care balanced against the chance of developing chorioamnionitis, cord compression and neonatal infection. , $^{2,3}$

The increase in time interval between rupture of membranes and onset of labour pains is associated with increase in the incidence of complications such as chorioamnionitis, endometritis, chronic abruption, cord compression, neonatal morbidity and neonatal sepsis. ${ }^{4}$ Active management is preferred after 34 weeks once fetal lung maturity is achieved thus reducing maternal and fetal complications. ${ }^{5}$

Several methods have been used to ripen the cervix and induce labour. Among them prostaglandins have been shown to be effective in cervical ripening as well as induction of labour. ${ }^{6}$ Misoprostol is a prostaglandin E1 methyl ester that stimulates myometrial contractions. Initially introduced for early pregnancy termination, in lower doses it is found to be effective for labour induction. ${ }^{7}$ Misoprostol is heat stable and does not require refrigeration for storage compared to the alternatives PGE2 gel or oxytocin. The cost of misoprostol tablet is also less than PGE2 gel or pessary and oxytocin injection. Studies have shown that misoprostol can be administered as various doses, at varied time intervals and through different routes such as oral, vaginal and sublingual. ${ }^{8-10}$

The additional advantage of oral and sublingual routes is a reduction in the number of per vaginal examinations when the patient is not in labour, decreasing the chance of iatrogenic ascending infection and increasing overall comfort for the patient. However, the ideal dose, route and frequency of administration still remain under investigation.

Most of the studies on induction of labour are conducted on women with intact membranes. Studies on women with PROM are limited. Also, there are only few studies comparing three routes of administration of misoprostol for induction of labour. Hence, the present study was undertaken with a view to compare the efficacy and safety of oral, vaginal and sublingual routes of administration of Misoprostol for induction of labour in women with PROM.

\section{METHODS}

The study was conducted in the Department of Obstetrics and Gynecology of a tertiary care hospital for a duration of three years. The study was approved by the institute ethics committee. This is an open label randomized controlled trial including 246 antenatal women. Participants were explained about the procedure and informed consent was obtained. The inclusion criteria were women who were admitted to labour ward with premature rupture of membranes after 34 weeks of gestation with a single live fetus in cephalic presentation, clear liquor, reassuring non-stress test and pre-induction Bishop score $\leq 6$. The exclusion criteria were women in established labour, suspected cephalopelvic disproportion or macrosomia, history of previous uterine surgery or lower segment cesarean section, antepartum hemorrhage, chorioamnionitis, active genital infection in the present pregnancy, contraindications to prostaglandins (glaucoma, asthma) and major fetal anomalies.

Women recruited for the study were randomised into 3 groups based on computer generated random numbers. A sterile speculum examination was performed to confirm PROM and note the color of liquor. The Bishop score was assessed before induction. All participants received prophylactic antibiotics (Ampicillin or Cephalosporin) as per the institute protocol. The time of spontaneous membrane rupture was noted. Group 1 received $50 \mu \mathrm{g}$ oral misoprostol 4th hourly, group 2 received $25 \mu \mathrm{g}$ vaginal misoprostol 4th hourly and group 3 received $50 \mu \mathrm{g}$ sublingual misoprostol 4 th hourly. A maximum of 4 doses was allowed in all three groups.

The administration of doses was repeated every 4 hours until active labour was achieved (i. e. minimum three uterine contractions lasting 45 seconds or more in 10 minutes or $>4 \mathrm{~cm}$ cervical dilatation) or a maximum of 4 doses was reached. If active labour was not established with four doses of misoprostol, and bishop score was $>6$, and contractions were inadequate, oxytocin infusion was commenced in some cases.

The participants and their neonates were followed until discharge and maternal and neonatal outcomes were noted. The primary outcome parameters studied wereinduction to active labour interval, induction to delivery interval, duration of first stage, duration of second stage, duration of third stage, failed induction after 4 doses and mode of delivery. The secondary outcome parameters were meconium staining of liquor, fetal heart rate abnormalities, APGAR scores at 1 minute and 5 minutes of birth, neonatal unit admission, maternal side effects like vomiting, diarrhea, shivering, pyrexia, maternal injuries and hyperstimulation.

\section{Statistical analysis}

The sample size of 246 was calculated based on previous studies assuming $80 \%$ power and $95 \%$ confidence interval. Descriptive statistics were used to analyse the subjects baseline characteristics like age, parity, period of gestation and duration of leaking. Percentages and frequencies were used for the description of categorical data and compared by using chi-square test or Fisher's exact test. Kolmogrov Smirnov test was used to assess 
the normality of continuous data. To present the normally distributed data, mean and standard deviation were used and for non-normal data, median with interquartile range was used. To compare the continuous variables between the three groups for parametric data, one-way analysis of variance (one way ANOVA) with post hoc analysis for multiple comparison was used and for non-parametric data, Kruskal-Wallis test was used. Univariate analysis was performed to determine the factors influencing the outcome.

Statistical analyses were carried out at 5\% level of significance and the $\mathrm{p}$ value $<0.05$ was considered significant.

\section{RESULTS}

The baseline demographic characters were similar in all three groups. The mean age was 24.4 years in the oral group, 24.7 years in the vaginal group and 24.1years in the sublingual group. Hence the age distribution in all 3 groups was comparable. There were more primigravidas compared to multigravidas in all the three groups. There were $63.8 \%$ primigravidas in the oral group, $60.2 \%$ in the vaginal group and $72.3 \%$ in the sublingual group which was not statistically significant. The mean duration of leaking was slightly higher in the sublingual group although this was not significant. The baseline parameters of the participants in the study are summarized in Table 1.

Table 1: Demographic characteristics of $50 \mu \mathrm{g}$ oral, $25 \mu \mathrm{g}$ vaginal and $50 \mu \mathrm{g}$ sublingual misoprostol groups.

\begin{tabular}{|llllll|}
\hline Parameters & Oral $(\mathbf{n = 8 0})$ & Vaginal $(\mathbf{n = 8 3})$ & Sublingual (n=83) & p value \\
\hline Mean Age (years) & $24.4 \pm 3.4$ & $24.7 \pm 3.8$ & $24.1 \pm 3.4$ & 0.52 \\
\hline \multirow{2}{*}{ Parity } & Primigravida & $51(63.8 \%)$ & $50(60.2 \%)$ & $60(72.3 \%)$ & 0.24 \\
\cline { 2 - 7 } & Multigravida & $29(36.2 \%)$ & $33(39.8 \%)$ & $23(27.7 \%)$ & 0.24 \\
\hline Mean duration of leaking (h) & $14.1 \pm 14$ & $13.1 \pm 10$ & $17 \pm 14$ & 0.12 \\
\hline Mean gestational age (weeks) & $38.3 \pm 1.7$ & $38.2 \pm 1.8$ & $38.3 \pm 1.9$ & 0.95 (NS) \\
\hline
\end{tabular}

Data are expressed as mean \pm SD or number of patients (percentages), $\mathrm{p}<0.05$ is considered significant.

Table 2: Pre induction bishop score for the three groups.

\begin{tabular}{lllll}
$\begin{array}{l}\text { Bishop } \\
\text { score }\end{array}$ & $\begin{array}{l}\text { Oral } \\
(\mathbf{n}-80)\end{array}$ & $\begin{array}{l}\text { Vaginal } \\
(\mathbf{n = 8 3})\end{array}$ & $\begin{array}{l}\text { Sublingual } \\
(\mathbf{n = 8 3})\end{array}$ & $\begin{array}{l}\mathrm{p} \\
\text { value }\end{array}$ \\
\hline 2 & $2(2.5 \%)$ & $0(0 \%)$ & $5(6 \%)$ & 0.06 \\
\hline 3 & $7(8.8 \%)$ & $11(13.3 \%)$ & $20(24.1 \%)$ & 0.02 \\
\hline 4 & $48(60 \%)$ & $51(61.4 \%)$ & $47(56.6 \%)$ & 0.81 \\
\hline 5 & $23(28.7 \%)$ & $21(25.3 \%)$ & $11(13.3 \%)$ & 0.06 \\
\hline
\end{tabular}

Data are expressed as percentages, $\mathrm{p}<0.05$ is considered significant.

The median Bishop score was taken as 4. Forty-eight $(60 \%)$ women in oral group, $51(61.4 \%)$ in vaginal group and $47(56.6 \%)$ in sublingual group had Bishop score of 4.

The Bishop score distribution of the participants prior to induction is tabulated in Table 2 .

\section{Primary outcome measures}

The mean duration between induction to active labour in the oral group was $7.52 \pm 4.8 \mathrm{~h}$, vaginal group was $7.75 \pm 4.1 \mathrm{~h}$ and sublingual group was $7.68 \pm 5.3 \mathrm{~h}$.

The $\mathrm{p}$ value for the comparison of means was 0.93 which was not statistically significant.

Table 3: Primary outcome measures.

\begin{tabular}{|lllll|}
\hline Labour characteristics & Oral & Vaginal & Sublingual & p value \\
\hline Time interval (induction - active labour) (h) & $7.52 \pm 4.8$ & $7.75 \pm 4.1$ & $7.68 \pm 5.3$ & 0.93 \\
\hline Time interval (induction - delivery) (h) & $10.9 \pm 5.9$ & $11.2 \pm 5.0$ & $11.4 \pm 6.6$ & 0.88 \\
\hline Time interval (active labour - delivery) (h) & $3.6 \pm 1.63$ & $3.6 \pm 1.21$ & $3.7 \pm 1.73$ & 0.85 \\
\hline Time interval (rupture of membranes - delivery) (h) & $23.7 \pm 16.4$ & $23.2 \pm 12.1$ & $27.1 \pm 17.7$ & 0.23 \\
\hline Duration of first stage (h) & $5.2 \pm 2.27$ & $5.7 \pm 2.16$ & $5.8 \pm 3.0$ & 0.32 \\
\hline Duration of second stage (min) & $34.8 \pm 15$ & $34.0 \pm 13$ & $32.6 \pm 14$ & 0.57 \\
\hline Duration of third stage (min) & $7.1 \pm 2.5$ & $6.8 \pm 1.6$ & $7.4 \pm 2.5$ & 0.19 \\
\hline
\end{tabular}

Data are expressed as mean \pm SD or number of patients (percentages), $\mathrm{p}<0.05$ is considered significant. 
The other major primary outcome of the study - mean duration between induction to delivery was $10.9 \pm 5.9 \mathrm{~h}$ in the oral group, $11.2 \pm 5.0 \mathrm{~h}$ in the vaginal group and $11.4 \pm 6.6 \mathrm{~h}$ in the sublingual group with $\mathrm{p}$ value 0.88 which was not significant statistically. Hence oral, vaginal and sublingual routes were equally effective for induction of labour. The various labour parameters and their means and standard deviations for the three groups are summarized in Table 3.

The mean number of doses required for induction of labour in the oral group was 2.58 , in the vaginal group was 2.67 , and in the sublingual group was 2.51 with a $p$ value of 0.5 which was not statistically significant. Majority in all the three groups required 2 to 3 doses of the drug. The number of doses required in each group is represented in Figure 1.

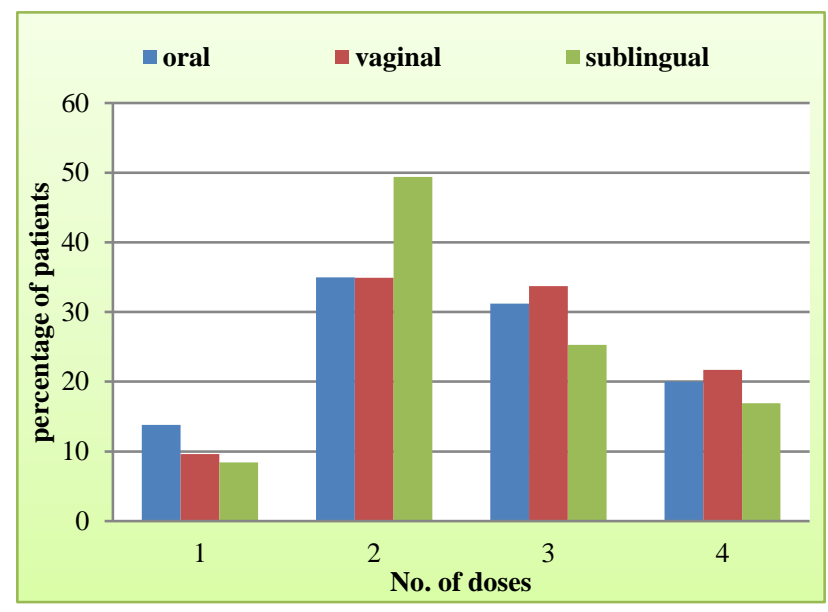

Figure 1: Number of doses.

The mode of delivery was comparable in oral, vaginal and sublingual misoprostol groups. Sixty four (80\%) patients in the oral group, $73(88 \%)$ in the vaginal group and $68(82 \%)$ in the sublingual group had spontaneous vaginal delivery. The caesarean section rates were $8.8 \%$ (7 women) in the oral group, 6\% (5 women) in the vaginal and $8.4 \%$ ( 7 women) in the sublingual group.

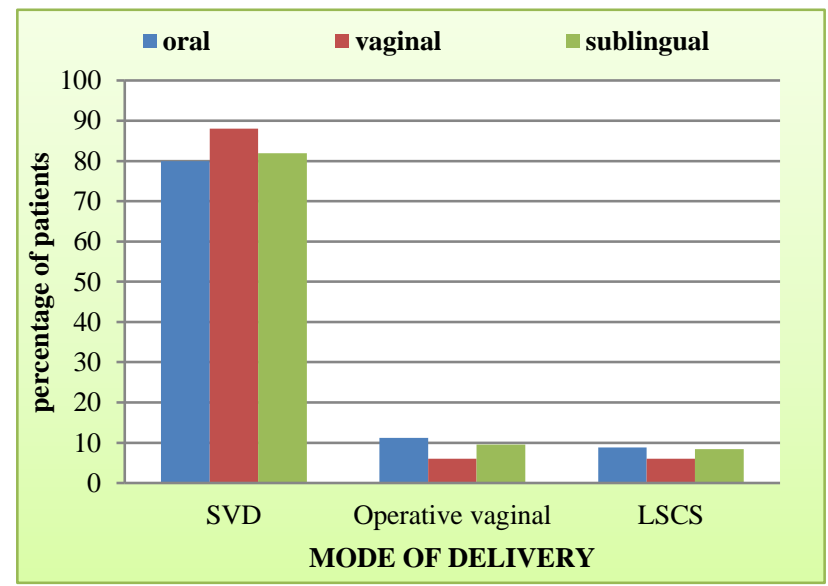

Figure 2: Mode of delivery.
Figure 2 represents the rates of mode of delivery for the women in three groups. The rate of various indications for cesarean section in the study are summarized in Table 4.

Table 4: Indications for lower segment caesarean section.

\begin{tabular}{|c|c|c|c|c|}
\hline Group & $\begin{array}{l}\text { Oral } \\
(n=80)\end{array}$ & $\begin{array}{l}\text { Vaginal } \\
(\mathrm{n}=\mathbf{8 3})\end{array}$ & $\begin{array}{l}\text { Sublingua } \\
\text { I }(\mathrm{n}=\mathbf{8 3})\end{array}$ & p value \\
\hline $\begin{array}{l}\text { Fetal } \\
\text { distress }\end{array}$ & $\begin{array}{l}3 \\
(3.8 \%)\end{array}$ & $\begin{array}{l}3 \\
(3.6 \%)\end{array}$ & $5(6.0 \%)$ & $0.70 \mathrm{~S}^{*}$ \\
\hline CPD & $0(0 \%)$ & $1(1.2 \%)$ & $2(2.4 \%)$ & $0.37 \mathrm{NS} * *$ \\
\hline $\begin{array}{l}\text { Failed } \\
\text { induction }\end{array}$ & $4(5 \%)$ & $\begin{array}{l}1 \\
(1.2 \%)\end{array}$ & $0(0 \%)$ & $0.062 \mathrm{NS} * *$ \\
\hline
\end{tabular}

*(S) Significant, ** (NS) Non-significant

\section{Secondary outcome measures}

Meconium stained liquor was found in $10 \%$ of the oral and $6.2 \%$ vaginal and $13.3 \%$ of the sublingual group. There were no significant differences among the groups with regard to the colour of liquor $(\mathrm{p}=0.71)$. Ten $(12.5 \%)$ women in the oral group, $5(6 \%)$ in the vaginal group and $10(12 \%)$ in the sublingual group required oxytocin although this was also not significant.

Table 5: Neonatal outcomes.

\begin{tabular}{|c|c|c|c|c|}
\hline Parameter & Oral & Vaginal & Sublingual & $\begin{array}{l}\text { p } \\
\text { value }\end{array}$ \\
\hline $\begin{array}{l}\text { APGAR }<7 \\
\text { at } 1 \mathrm{~min}\end{array}$ & $\begin{array}{l}12 \\
(16 \%)\end{array}$ & $\begin{array}{l}6 \\
(7.2 \%)\end{array}$ & $17(20.5 \%)$ & 0.04 \\
\hline $\begin{array}{l}\text { APGAR }<7 \\
\text { at } 5 \mathrm{~min}\end{array}$ & $\begin{array}{l}4 \\
(4.8 \%)\end{array}$ & $\begin{array}{l}2 \\
(2.4 \%)\end{array}$ & $6(7.2 \%)$ & 0.2 \\
\hline $\begin{array}{l}\text { Neonatal } \\
\text { intensive } \\
\text { unit } \\
\text { admission }\end{array}$ & $\begin{array}{l}8 \\
(10 \%)\end{array}$ & $\begin{array}{l}3 \\
(3.6 \%)\end{array}$ & $12(14.5 \%)$ & 0.055 \\
\hline
\end{tabular}

The number of neonates with APGAR score $<7$ at 1 minute of birth was highest in the sublingual group and lowest in vaginal group which was statistically significant in our study $(\mathrm{p}=0.04)$. APGAR score $<7$ at 5 minutes was not significantly different among the three groups $\mathrm{p}=$ 0.2 ). The neonatal outcomes are summarized in Table 5.

Eight (10\%) neonates in the oral group, $3(3.6 \%)$ in the vaginal group and $12(14.5 \%)$ in the sublingual group required Neonatal Intensive Care Unit admission. Although the difference was not statistically significant ( $\mathrm{p}=0.055)$, vaginal group had the least number of Neonatal intensive unit admissions followed by oral and sublingual groups. The different indications for Neonatal Intensive Unit admission for the neonates of women in the three groups is represented in Figure 3.

The lowest number of side effects, although not statistically significant, were found in the vaginal group. Sublingual group had higher rates of hyperstimulation 
and fetal heart rate abnormalities compared to oral and vaginal groups. The rate of side effects is represented in Figure 4.

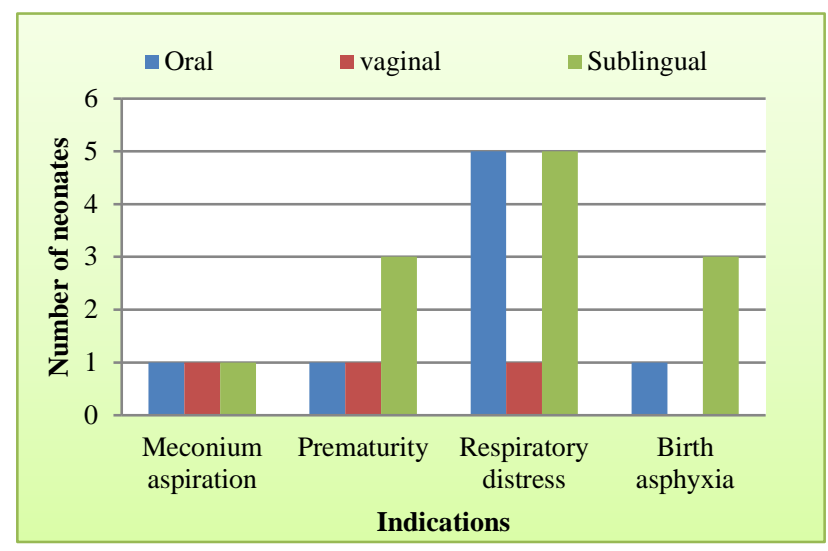

Figure 3: Indications for NICU admission.

Univariate analysis showed that the primary outcome parameters - duration between induction to active labour, duration between induction to delivery were dependent on Bishop score in all the three groups. There was an inverse relationship between Bishop score and the afore mentioned parameters. Lower the Bishop score, longer the time taken for delivery. These parameters were also dependent on period of gestation. Lesser the gestational age, longer the time taken to achieve delivery. The primary outcomes were independent of the parity status.

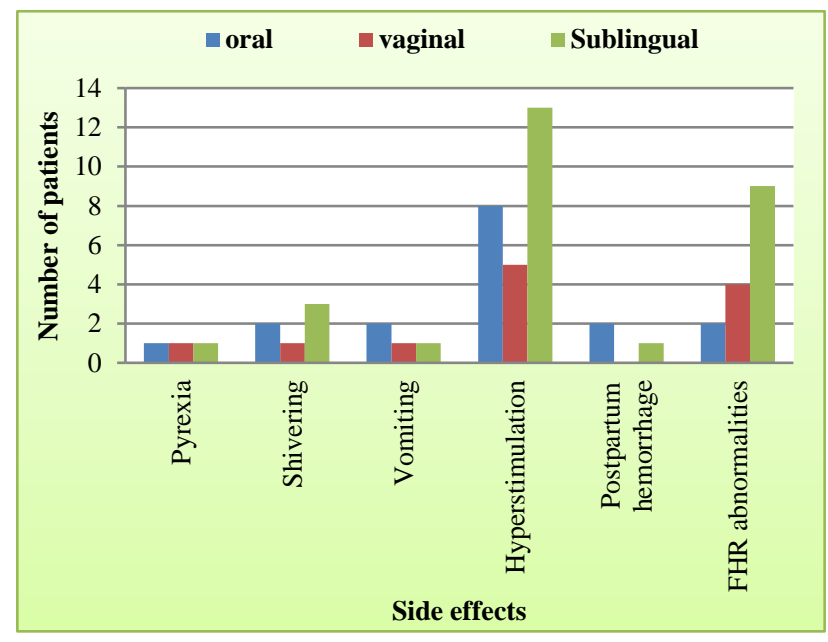

Figure 4: Maternal side effects.

\section{DISCUSSION}

The present study did not detect any significant difference between the three groups with regard to induction to active labour interval or induction to delivery interval. There are several studies comparing oral vs vaginal routes of misoprostol and few studies comparing oral vs sublingual, and vaginal vs sublingual routes for induction of labour. These studies have used different formulations and different doses. A study by Elhassan et al compared all the three routes of misoprostol for labour induction and the mean induction to delivery interval was shortest in the sublingual group (13.3h) which was significant. ${ }^{11}$ In contrast our study did not detect a major difference between the groups. The studies by Hall et al and Paungmora et al concluded there was no significant difference in induction to delivery time between the oral and vaginal groups in concordance with our study. ${ }^{12,13}$

The spontaneous vaginal delivery rate in the present study was $80 \%$ in the oral group, $88 \%$ in the vaginal group and $82 \%$ in the sublingual group. The spontaneous vaginal delivery rate in the study by Mehrotra et al was $83.3 \%$ in the oral and $83.8 \%$ in the vaginal group which was consistent with our results. ${ }^{14}$ Elhassan et al showed that the three groups oral, vaginal and sublingual had almost equal rates of spontaneous vaginal delivery. ${ }^{11}$ Bartusevicius et al in their study found that $83 \%$ in the sublingual misoprostol group and $76 \%$ in the vaginal misoprostol group delivered vaginally within 24 hours of induction. ${ }^{15}$ The study by Zahran et al concluded that $70.4 \%$ patients delivered vaginally in the sublingual group and $66.7 \%$ in the vaginal group with no significant difference. ${ }^{16}$ Present study concurs with these findings.

The present study showed an instrumental delivery rate of $11.2 \%$ in the oral group, $6 \%$ in the vaginal group and $9.6 \%$ in the sublingual group which was comparable to the study by Hall et al with an instrumental delivery rate of $8 \%$ in the oral group and $6 \%$ in the vaginal group. ${ }^{12}$ The present study had caesarean section rate of $8.8 \%$ in the oral group, $6 \%$ in the vaginal group and $8.4 \%$ in the sublingual group. The rate of caesarean section in the study by Mehrotra et al was $16.7 \%$ in the oral group and $16.2 \%$ in the vaginal group. ${ }^{14}$ Hall et al showed a caesarean section rate of $15 \%$ in the oral group and $17 \%$ in the vaginal group in their study. ${ }^{12}$ The overall caesarean section rate in our study is low compared to rest of the studies which could be because of the difference in the study population, higher pre-induction Bishop score and due to the practice of instrumental delivery in carefully selected cases. The commonest indication for caesarean section in all three groups was non-reassuring fetal heart rate. Other indications for caesarean section were failed induction, non-progress of labour and cephalopelvic disproportion.

In the present study 12 neonates in the oral group, 6 in the vaginal group and 17 in the sublingual group had 1 minute APGAR score $<7$ which was statistically significant. There was no neonatal mortality in all the three groups. The 5 minutes APGAR score $<7$ was comparable in all three groups. Therefore, there was a need for immediate neonatal resuscitation mainly in the sublingual group but the long term neonatal outcomes were similar in all three groups.

Although the difference was not statistically significant, vaginal group had the least number of Neonatal Unit admissions followed by oral and then sublingual groups. 
The study by Feitosa et al and Zahran et al found no significant differences between the vaginal and sublingual misoprostol groups. ${ }^{16,17}$ The study by Shetty et al comparing oral and sublingual routes of misoprostol found the rate of admission to be $12 \%$ in the oral group and $10 \%$ in the sublingual group. ${ }^{18}$ These studies are in agreement with our findings. The main indications for Neonatal Unit admission in all the studies were respiratory distress, low APGAR score and birth asphyxia. The present study did not compare the cord blood $\mathrm{pH}$ of the babies in the three groups

The side effect profile was comparable among the groups. The rate of hyperstimulation in the present study was $10 \%$ in the oral group, $6 \%$ in the vaginal group and $15.6 \%$ in the sublingual group. The study by Shetty et al showed a rate of $0.8 \%$ hyperstimulation in the oral group and $4.9 \%$ in the vaginal group. ${ }^{19}$ The study by Mehrotra et al showed no hyperstimulation in the oral group but $4.4 \%$ in the vaginal group. ${ }^{14}$ These studies used $50 \mu \mathrm{g}$ vaginal misoprostol whereas in the present study $25 \mu \mathrm{g}$ vaginal misoprostol was used. The study by Shetty et al showed the hyperstimulation rates as $1 \%$ in the sublingual group and nil in the oral group. ${ }^{18}$ According to our study, the rate of hyperstimulation was highest in the sublingual group, although not significant statistically. There was one case of annular cervical tear in the sublingual group probably due to uterine hyperstimulation when the cervix was not fully dilated. Hence sublingual misoprostol needs to be used with caution.

Present study also found fetal heart rate abnormalities without hyperstimulation in some women owing to decreased liquor and cord compression which was more in the sublingual group. The incidence of chorioamnionitis was low in our study owing to proper case selection and prophylactic antibiotics given to the participants. We followed appropriate randomization protocols but could not incorporate blinding of subjects and caregivers in the study. Our study did not assess the patient satisfaction rate with the different routes, which if analyzed could have offered insight into the patients preference to a particular route as all three were found equally effective.

\section{CONCLUSION}

The study demonstrated that oral, vaginal and sublingual routes of administration of misoprostol were equally efficacious for labour induction in women with premature rupture of membranes after 34 weeks. The sublingual route had higher incidence of low APGAR scores at one minute for the neonate and hence the need for immediate resuscitation was higher in this group, but the APGAR scores evaluated after 5 minutes were comparable among the three groups with no significant difference. There was no long term neonatal morbidity. Although there were more number of side effects reported in the sublingual misoprostol group, the safety profiles of the three routes were comparable.

Funding: No funding sources

Conflict of interest: None declared

Ethical approval: The study was approved by the Institutional Ethics Committee

\section{REFERENCES}

1. Gunn GC, Mishell DR Jr, Morton DG. Premature rupture of the fetal membranes. A review. Am J Obstet Gynecol. 1970 Feb;106(3):469-83.

2. Duff P. Premature rupture of the membranes in term patients. Semin Perinatol. 1996 Oct;20(5):401-8.

3. ACOG practice bulletin No.139: premature rupture of membranes. Obstet Gynecol. 2013;122:918-30.

4. Horvath B, Grasselly M, Bodecs T, Boncz I, Bodis J. Histological chorioamnionitis is associated with cerebral palsy in preterm neonates. Eur J Obstet Gynecol Reprod Biol. 2012 Aug 1;163(2):160-4.

5. Tan BH, Hannah ME. Prostaglandins for prelabour rupture of membranes at or near term. Cochrane Database Syst Rev. 2000;(2):CD000178.

6. Cunningham FG, Leveno KJ, Bloom SL, Hauth JC, Rouse D, Spong C. Labour induction. Williams obstetrics. $23^{\text {rd }}$ ed. McGraw Hill Companies, Inc. USA;2010:501.

7. Weeks A, Alfirevic Z, Faundes A, Hofmeyr GJ, Safar P, Wing D. Misoprostol for induction of labour with a live fetus. Int J Gynaecol Obstet. 2007 Dec;99 Suppl 2:S194-7.

8. Hofmeyr GJ, Gülmezoglu AM, Pileggi C. Vaginal misoprostol for cervical ripening and induction of labour. Cochrane Database Syst Rev. 2010;(10):CD000941.

9. Alfirevic Z, Weeks A. Oral misoprostol for induction of labour.. Cochrane Database Syst Rev. 2006 Apr;(2):CD001338.

10. Shetty A, Danielian P, Templeton A. Sublingual misoprostol for the induction of labour at term. Am J Obstet Gynecol. 2002 Jan;186(1):72-6.

11. Elhassan EM, Nasr AM, Adam I. Sublingual compared with oral and vaginal misoprostol for labour induction. Int $\mathrm{J}$ Gynaecol Obstet. 2007;97(2):153-4.

12. Hall R, Duarte-Gardea M, Harlass F. Oral versus vaginal misoprostol for labour induction. Obstet Gynecol. 2002 Jun;99(6):1044-8.

13. Paungmora N, Herabutya Y, O-Prasertsawat P, Punyavachira P. Comparison of oral and vaginal misoprostol for induction of labour at term: a randomized controlled trial. J Obstet Gynaecol Res. 2004 Oct;30(5):358-62.

14. Mehrotra S, Singh U, Gupta HP. A prospective double blind study using oral versus vaginal misoprostol for labour induction. J Obstet Gynecol. 2010; 0(5):461-4.

15. Bartusevicius A, Barcaite E, Krikstolaitis R, Gintautas V, Nadisauskiene R. Sublingual compared 
with vaginal misoprostol for labour induction at term: a randomised controlled trial. BJOG. 2006 Dec;113(12):1431-7.

16. Zahran KM, Shahin AY, Abdellah MS, Elsayh KI. Sublingual versus vaginal misoprostol for induction of labour at term: a randomized prospective placebocontrolled study. J Obstet Gynaecol Res. 2009 Dec;35(6):1054-60.

17. Feitosa FE, Sampaio ZS, Alencar CA Jr, Amorim MM, Passini R Jr. Sublingual vs. vaginal misoprostol for induction of labour. Int J Gynecol Obstet. 2006 Aug;94(2):91-5

18. Shetty A, Mackie L, Danielian P, Rice P, Templeton A. Sublingual compared with oral misoprostol in term labour induction: a randomised controlled trial. BJOG. 2002 Jun;109(6): 645-50.

19. Shetty A, Danielian P, Templeton A. A comparison of oral and vaginal misoprostol tablets in induction of labour at term. BJOG. 2001 Mar;108(3):238-43.

Cite this article as: Galidevara C, Chaturvedula L, Habeebullah S. Comparison of oral, vaginal and sublingual misoprostol for induction of labour in premature rupture of membranes after 34 weeks of gestation: a randomized controlled trial. Int J Reprod Contracept Obstet Gynecol 2018;7:1340-6. 